\title{
Hydatid Cyst of Para-Spinal Muscles as a Rare Cause of Back Pain in a Woman: A Case Report and Review of Literature
}

\author{
Hamidreza Khorshidi' ${ }^{1}$, Mehrdad Taghipour ${ }^{1 *}$, Mohammad Moslemi' ${ }^{1}$, Leili Ebrahimi Farsangi ${ }^{2}$ \\ ${ }^{1}$ General Surgery Department, Hamadan University of Medical Sciences, Hamadan, Iran \\ ${ }^{2}$ Alborz University of Medical Sciences, Shahid Rajaee Hospital, Karaj, Iran \\ Email: *mehrdadtaghipour@gmail.com
}

How to cite this paper: Khorshidi, H., Taghipour, M., Moslemi, M. and Farsangi, L.E. (2020) Hydatid Cyst of Para-Spinal Muscles as a Rare Cause of Back Pain in a Woman: A Case Report and Review of Literature. Case Reports in Clinical Medicine, 9, 184-190. https://doi.org/10.4236/crcm.2020.97026

Received: April 30, 2020

Accepted: July 6, 2020

Published: July 9, 2020

Copyright $\odot 2020$ by author(s) and Scientific Research Publishing Inc. This work is licensed under the Creative Commons Attribution International License (CC BY 4.0).

http://creativecommons.org/licenses/by/4.0/

\begin{abstract}
Introduction: Hydatid cyst formation is rare in organs such as muscle, bone and spine. Para-spinal involvement is an uncommon finding with a prevalence of less than $0.5 \%$ in the literatures. Presentation of Case: In the present paper, we reported a case of primary hydatid cyst in lumbar para-spinal area. The patient presented with complaint of chronic back pain and swelling in right thoracolumbar area. A suspicious mass was revealed in lumbar spine x-ray presenting as multi-loculated cystic mass on further evaluation by magnetic resonance imaging (MRI). The patient underwent surgery and the cyst was excised completely. Histopathological evaluations confirmed the hydatid disease. Discussion: Hydatid disease is a zoonotic infectious disease caused by Echinococcus granulosus. The parasitic cysts can form in any part of the host body. The liver and lungs are the most commonly involved organs. The occurrence of these lesions in certain areas such as para-spinal muscles is rare. The cystic mass is detected by radiologic modalities and is confirmed by pathologic examination. Surgery is the mainstay of treatment. Conclusion: Hydatid disease should be on differential diagnosis list facing a cystic lesion in any part of the body especially in the endemic areas. Moreover, radiologic and serologic assessments are important in confirming the diagnosis.
\end{abstract}

\section{Keywords}

Echinococcosis, Hydatid Cyst, Muscle, Para-Spinal

\section{Introduction}

Hydatid disease is due to infection by the tapeworm Echinococcus granulosus in 
its larval or cystic stage. The tapeworm lives in canids that are infected by eating the viscera of sheep containing hydatid cysts [1] [2] [3]. Hydatid disease is more common in sheep-raising areas, where dogs have access to infected offal. These areas include: New Zealand, Greece, Spain, Australia, South America, the Middle East and generally countries with low socio-economic conditions [4]. It commonly develops in the right lobe of the liver (65\% to $75 \%$ ) and the lungs (25\% $30 \%)$. Involvement of other parts of the body like the bones, muscles, spine, spleen, pericardium and myocardium is rare [5] [6]. Muscular hydatid cyst is uncommon due to unfavorable environment caused by lactic acid production in this organ. It constitutes only $2 \%-3 \%$ of all the disease cases [7]. Here, we present a rare case of paraspinal hydatid cyst.

\section{Case Presentation}

A 36-year-old female presented to our surgical clinic with chief complaint of chronic pain in her right thoracolumbar area and sensation of fullness in the right lumbar paraspinal area for a duration of time about 4 months.

There was no history of unintentional weight loss, hematuria, abdominal pain, fever or antecedent trauma. Drug history was also negative.

On physical examination, no sensory deficit was detected, the straight leg rising test was negative and all tendon reflexes were in the range of normal.

A diffused non-tender swelling in right paraspinal muscle in thoracolumbar area was palpated. Blood workups including liver and renal function tests were insignificant.

There no abnormal finding in abdominal ultrasound and chest X-ray evaluation.

Ultrasound examination of the involved paraspinal area showed a multi- lobulated hyperechoic cystic lesion with thick wall measuring $6 * 3 \mathrm{~cm}$ in greatest diameter. The hydatid cyst was at the top of differential diagnosis list. MRI of lumbar spine demonstrated a multilocular encapsulated cystic lesion with regular boarder in para spinal muscles. The signal intensity of the cystic portion was low on T1 sequences and uniformly high on T2 sequences. There was no evidence of mass effect on adjacent bones or any sign of bone destruction (Figure 1). The patient was admitted in to the surgery ward with the diagnosis of hydatid cyst of paraspinal muscle based on the clinical and radiologic findings and underwent surgery. The lesion was excised completely (Figure 2). Definitive diagnosis was confirmed by histopathologic evaluation. 12 months later at the final follow up, the patient was symptom free with all physical and laboratory results within normal range.

\section{Discussion}

Echinococcosis is caused by larva stage of the tape worm Echinococcus genus mostly echinococcus granulosus. Echinococcus granulosus life cycle comprises of a definitive carnivore host feeding off an herbivore intermediate host [4]. The adult Echinococcus granulosus dwells in the small intestine of the definitive 

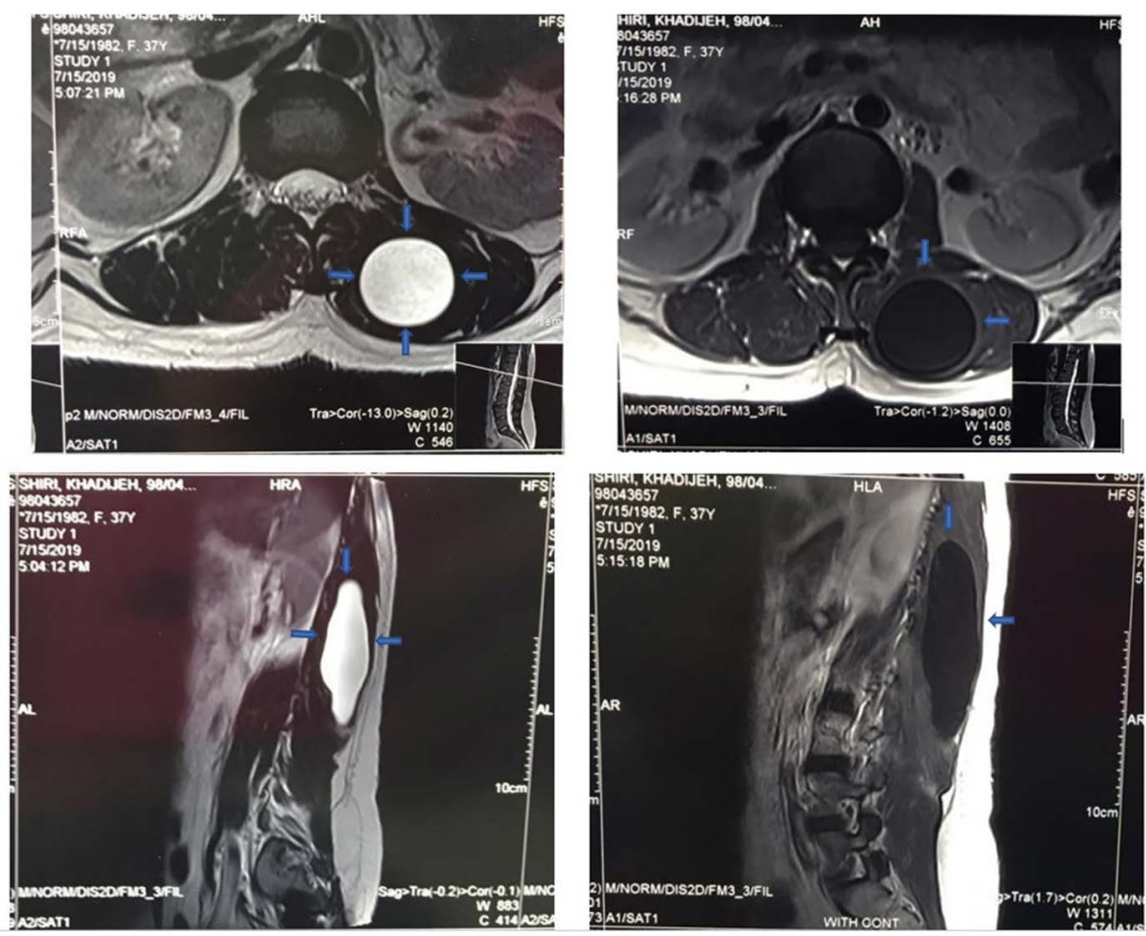

Figure 1. MRI of lumbar spine demonstrating a cystic lesion.

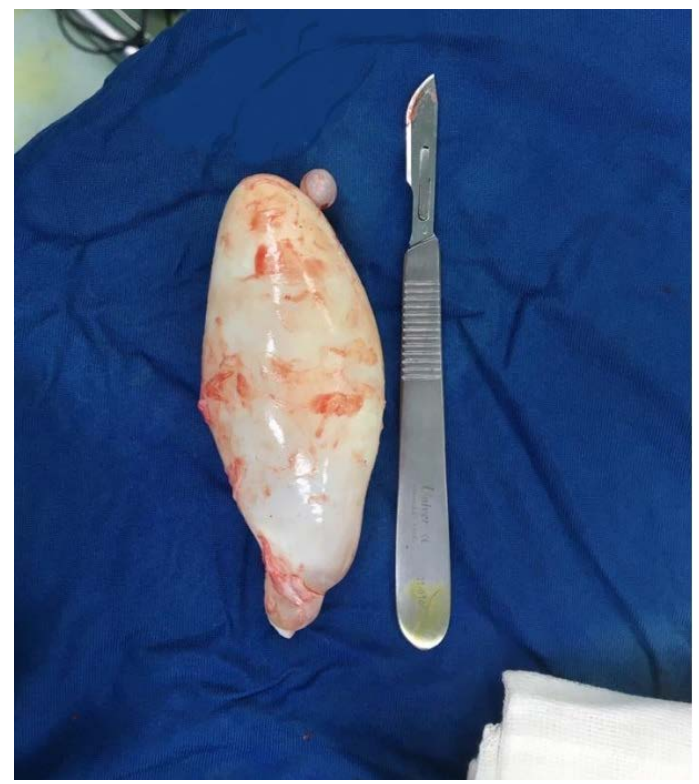

Figure 2. The hydatid cysts in para-spinal area were completely resected.

host. Eggs are excreted in the feces, after ingestion by a suitable intermediate host, eggs hatch in the small intestine and release oncospheres. They penetrate the intestinal wall and migrate through the circulatory system into different organs, especially the lungs and the liver. The oncospheres change into a thickwalled hydatid cyst in these organs and enlarges gradually, producing protoscolices and daughter cysts that fill the cyst interior. The definitive host becomes infected by swallowing the cyst-containing organs of the infected intermediate 
host. After ingestion, the protoscolices evaginate, attach to the intestinal mucosa, and develop into adult phase. Humans are aberrant intermediate hosts, and become infected by ingesting eggs. Oncospheres are released in the intestine, and hydatid cysts develop in a variety of organs. If cysts rupture, the liberated protoscolices may create secondary cysts in other sites within the body (secondary echinococcosis) [5]. Liver and lungs are the most common sites for cystic echinococcosis (CE) but the disease can be seen in any organ of the body. Musculoskeletal system is reported to be the fifth common site of cystic echinococcosis (CE) after lung, liver, central nervous system (CNS) and orbit by Geramizadeh. Paraspinal involvement is even more uncommon [6] [7] [8]. Muscular CE is mostly associated with hepatic involvement but rare isolated primary CE of skeletal muscle has been reported [9] [10] [11] [12]. High lactic acid level of muscle and muscle contraction make the muscle a harsh environment to attach to and survive in [13]. The proposed theory for translocation of parasite to paraspinal muscle is through the portal system to the IVC from where the parasite gets access to lumbar plexus during Valsalva maneuver occurring during daily activities [13] [14]. Nonspecific clinical findings of CE make it difficult to diagnose the disease just based on physical examination [6] [15]-[20]. CE has a slow development course which eventually become symptomatic as the cyst exert pressure over adjacent organs and structures depending on location and the size of the cyst. It may present with pain, palpable mass, obstruction of organs and ducts leading to swelling, inflammation and infection [6]. Different serologic tests such as ELISA for anti-echinococcal antibody, hemagglutination test, immunoelectrophoresis (IEP) have been used with variable success [12]. Although serologic tests are reported to have an acceptable sensitivity for intra-abdominal disease they suffer low sensitivity for other involved sites [18]. ELISA has been reported to have a sensitivity and specificity rate of $95 \%$ and $94 \%$ respectively [21]. Serologic tests are reported to be falsely negative in half of isolated intramuscular hydatidosis because of capsulate nature of the disease [6] [10] [19]. Different imaging modalities such as U/S, CT scan and MRI can be used to assist making the diagnosis with CT scan and MRI reported to be highly accurate [15] [22]. Our patient was a 36-year-old female who presented with chronic back pain and bulging in right thoracolumbar area. MRI and U/S were helpful supplements to physical examination in narrowing the differential diagnosis in this case and the final diagnosis of hydatid cyst in paraspinal muscles was confirmed after successful and complete excision of the lesion by histopathologic assessment.

Surgery is usually the optimal therapeutic strategy for hydatid cyst. Laparoscopic evacuation is indicated in some types of the cyst [23]. Moreover, in case of recurrence and high risk of contamination, non-toxic scolocidal agents or combined chemotherapy, particularly with Albendazole may be a proper alternative option.

\section{Conclusion}

Hydatid cyst should be included in differential diagnosis of cystic lesions in any 
area of the body, particularly in endemic areas. Radiologic assessments can be of great help reaching the final diagnosis. Surgical resection of the lesion is the therapeutic option of choice among several methods.

\section{Sources of Funding}

This research did not receive any specific grant from funding agencies in the public, commercial, or not-for-profit sectors.

\section{Ethics Approval}

Not applicable.

\section{Consent for Publication}

Written informed consent was obtained from the patient to participate in the treatment and publication.

\section{Author's Contribution}

Hamidreza Khorshidi: Paper conception, supervised the work.

Mehrdad Taghipour: Data acquisition, data interpret and editing the manuscript.

Mohammad Moslemi: Writing of the manuscript and clinical data collection.

Leili Ebrahimi Farsangi: Data acquisition and clinical procedures of the study.

\section{Acknowledgements}

We would like to thank Dr Mina Rostami for her helpful suggestions in preparing the manuscript.

\section{Conflicts of Interest}

The authors declare no conflicts of interest regarding the publication of this paper.

\section{References}

[1] Salehi, H., Salimi Boroujeni, K. and Yaghoubi, S. (2019) Report of a Hydatid Cyst Case with Biceps Brachii Involvement. Advanced Biomedical Research, 8, 23. https://doi.org/10.4103/abr.abr_101_18

[2] Velasco-Tirado, V., Alonso-Sardón, M., Lopez-Bernus, A., Romero-Alegría, A., Javier Burguillo, F. and Muro, A. (2018) Medical Treatment of Cystic Echinococcosis: Systematic Review and Meta-Analysis. BMC Infectious Diseases, 18, 306. https://doi.org/10.1186/s12879-018-3201-y

[3] Pakala, T., Molina, M. and Wu, G.Y. (2016) Hepatic Echinococcal Cysts: A Review. Journal of Clinical and Translational Hepatology, 4, 39-46. https://doi.org/10.14218/JCTH.2015.00036

[4] Grosso, G., Gruttadauria, S., Biondi, A., Marventano, S. and Mistretta, A. (2012) Worldwide Epidemiology of Liver Hydatidosis Including the Mediterranean Area. World Journal of Gastroenterology, 18, 1425-1437. 


\section{https://doi.org/10.3748/wig.v18.i13.1425}

[5] CDC (2019) Prevention CfDCa. Parasites-Echinococcosis. https://www.cdc.gov/parasites/echinococcosis/biology.html

[6] Geramizadeh, B. (2013) Unusual Locations of the Hydatid Cyst: A Review from Iran. Iranian Journal of Medical Sciences, 38, 2-14.

[7] Atalay, F., Orug, T., Arda, K. and Tosun, O. (2003) An Unusual Case of Hydatid Disease Located in the Erector Spinae Muscle. JBR-BTR, 86, 329-331.

[8] Sadeghian, H. and Motiei-Langroudi, R. (2019) Hydatid Cyst in the Lumbar Paravertebral Muscle: A Case Report. Cureus, 11, e5353. https://doi.org/10.7759/cureus.5353

[9] Din, D.P.M.U., Anjum, W.A., Ahmad, M.L., Rehman, K.A., Ahmad, G.B. and Gulshan, W.N. (2018) Primary Para-Vertebral Hydatid Cyst in the Sub-Occipital Area of the Neck: An Unusual Case of Echinococcosis. Egyptian Journal of Neurosurgery, 33, 16. https://doi.org/10.1186/s41984-018-0015-6

[10] Bilgic, S., Kose, O., Sehirlioglu, A., Safaz, I. and Ozkan, H. (2009) Primary Paraspinal Hydatid Cyst Treated with Puncture, Aspiration, Injection and Re-Aspiration (PAIR) Technique: A Case Report. European Spine Journal, 18, 165-167. https://doi.org/10.1007/s00586-008-0737-3

[11] Duncan, G.J. and Tooke, S.M. (1990) Echinococcus Infestation of the Biceps Brachii. A Case Report. Clinical Orthopaedics and Related Research, 261, 247-250. https://doi.org/10.1097/00003086-199012000-00029

[12] Garcia-Diez, A.I., Ros Mendoza, L.H., Villacampa, V.M., Cozar, M. and Fuertes, M.I. (2000) MRI Evaluation of Soft Tissue Hydatid Disease. European Radiology, 10, 462-466. https://doi.org/10.1007/s003300050077

[13] Sener, R.N., Calli, C., Kitis, O. and Yalman, O. (2001) Multiple, Primary Spinal-Paraspinal Hydatid Cysts. European Radiology, 11, 2314-2316. https://doi.org/10.1007/s003300000771

[14] Schnepper, G.D. and Johnson, W.D. (2004) Recurrent Spinal Hydatidosis in North America. Neurosurgical Focus, 17, 1. https://doi.org/10.3171/foc.2004.17.6.8

[15] Polat, P., Kantarci, M., Alper, F., Suma, S., Koruyucu, M.B. and Okur, A. (2003) Hydatid Disease from Head to Toe. Radiographics, 23, 475-494. https://doi.org/10.1148/rg.232025704

[16] Mousavi, S.R., Samsami, M., Fallah, M. and Zirakzadeh, H. (2012) A Retrospective Survey of Human Hydatidosis Based on Hospital Records during the Period of 10 Years. Journal of Parasitic Diseases, 36, 7-9. https://doi.org/10.1007/s12639-011-0093-9

[17] Hamamci, E.O., Besim, H. and Korkmaz, A. (2004) Unusual Locations of Hydatid Disease and Surgical Approach. ANZ Journal of Surgery, 74, 356-360. https://doi.org/10.1111/j.1445-1433.2004.02981.x

[18] Engin, G., Acunas, B., Rozanes, I. and Acunas, G. (2000) Hydatid Disease with Unusual Localization. European Radiology, 10, 1904-1912. https://doi.org/10.1007/s003300000468

[19] Dahniya, M.H., Hanna, R.M., Ashebu, S., Muhtaseb, S.A., el-Beltagi, A., Badr, S., et al. (2001) The Imaging Appearances of Hydatid Disease at Some Unusual Sites. The British Journal of Radiology, 74, 283-289. https://doi.org/10.1259/bjr.74.879.740283

[20] Taori, K., Sanyal, R., Rathod, J., Mahajan, S., Jajoo, G., Saxena, V., et al. (2006) CT Appearances of Hydatid Disease at Various Locations. Australasian Radiology, 50, 298-305. https://doi.org/10.1111/j.1440-1673.2006.01588.x 
[21] Shambesh, M.A., Craig, P.S., Macpherson, C.N., Rogan, M.T., Gusbi, A.M. and Echtuish, E.F. (1999) An Extensive Ultrasound and Serologic Study to Investigate the Prevalence of Human Cystic Echinococcosis in Northern Libya. The American Journal of Tropical Medicine and Hygiene, 60, 462-468. https://doi.org/10.4269/ajtmh.1999.60.462

[22] Von Sinner, W., te Strake, L., Clark, D. and Sharif, H. (1991) MR Imaging in Hydatid Disease. American Journal of Roentgenology, 157, 741-745. https://doi.org/10.2214/ajr.157.4.1892028

[23] Pamir, M.N., Ozduman, K. and Elmaci, I. (2002) Spinal Hydatid Disease. Spinal Cord, 40, 153-160. https://doi.org/10.1038/sj.sc.3101214 